\title{
VIOLÊNCIAS NO FUTEBOL ARGENTINO: O QUÊ ESTÁ EM JOGO? QUAIS SÃO OS PARALELOS COM O BRASIL?
}

\section{DIFFERENT FORMS OF VIOLENCE IN THE ARGENTINIAN FOOTBALL: WHAT IS AT STAKE? WHAT ARE THE PARALLELS WITH BRAZIL?}

\author{
SEGURA, Fernando* \\ WOOD, David ${ }^{\star *}$ \\ JUNQUEIRA, Ricardo ${ }^{* * *}$ \\ GOMES, Vitor ${ }^{* * * *}$ \\ NETTO, Thaissa ${ }^{* * * *}$
}

\begin{abstract}
RESUMO
Este artigo analisa episódios de agressões, incluindo mortes, relacionadas com o futebol na Argentina, identificadas na imprensa (impressa e digital) entre os anos 2006 e 2018 a partir de um levantamento da ONG Salvemos al Futbol. O objetivo é, portanto, refletir sobre atmosfera de violência em torno dos jogos na Argentina, assim como gerar uma aproximação para o contexto brasileiro, com ênfase na cidade de Goiânia. Nossa análise explora novas formas de violência, incluindo a mortes por torcedores da mesma equipe. Embora os "grandes meios de comunicação" tendem a culpar os grupos conhecidos como barras-bravas, mesma situação com o que acontece com as torcidas organizadas no Brasil, nosso intuito é analisar diferentes cenários e avaliar a variedade de interesses envolvidos. Isto inclui também os "arranjos" com a Polícia e outras autoridades, bem como as agressões entre os protagonistas do jogo em si. Por conseguinte, esperamos atualizar os debates recentes ao revelar novas tendências e sugerir hipóteses para futuras pesquisas e políticas públicas, tanto para a Argentina quanto para o Brasil.
\end{abstract}

Palavras-chave: Atores, Argentina, Brasil, mortes, futebol, violência.

\begin{abstract}
This article analyzes episodes of aggressions, including deaths, related to soccer in Argentina, identified in the press (printed and digital) between 2006 and 2018 from the work of the NGO Let's Save the Soccer (Salvemos al Fútbol). The purpose is then to present a case study in order to reflect the internal atmosphere of violence around games in Argentina and some reflections about the Brazilian contexts, particularly the one of the city of Goiânia, capital of the state of Goiás. Our analysis explores new forms of violence, such as the deaths by supporters of the same team. Even though the corporative media tend to blame groups known as
\end{abstract}

\footnotetext{
*Professor Visitante (2016-2020) no Programa de Pós-Graduação em Sociologia da Universidade Federal de Goiás (UFG), pesquisador filiado ao CIDE (México). Este artigo contitui uma contribuição à pesquisa em andamento em parceria com a Universidade de Sheffield, Inglaterra a partir de um Award da British Academy. Doutor em Sociologia pela Escola de Altos Estudos em Ciências Sociais (EHESS) de Paris. Colaborador da ONG Salvemos al Fútbol (Argentina).

"* Professor Permanente de Estudos Latino-Americanos na Escola de Línguas e Cultura da Universidade de Sheffield, Inglaterra. Coordenador da rede Levelling the Field sobre estudos em torno ao futebol feminino na América Latina e na Inglaterra. Ex-presidente (2019) da Associação Britânica de estudos LatinoAmericanos. Doutor em estudos Latino-Americanos, com foco no Perú, pela Universidad de Exter, Inglaterra.

${ }^{* * *}$ Mestrando no Programa de Pós-Graduação em Sociologia da Universidade Federal de Goiás. Formado em Direito pela PUC-GO.

***x Mestrando no Programa de Pós-Graduação em Sociologia da Universidade Federal de Goiás. Bacharel em Ciências Sociais pela UFG.

***** Bacharel e Licenciada em Educação Física pela PUC-GO. Pós-graduada em Musculação e personal trainer pelo CEAFI-GO. Estudante de Sociologia pela Estágio-GO.
} 
barras-bravas, as the same occurs with the organized fans in Brazil, called torcidas organizadas, we try to analyze here different scenarios and evaluate the variety of interests involved, which include "arrangements" public bodies and authorities, as well as the aggression between the protagonists of the game itself. Therefore, we hope to update recent debates by revealing trends and suggesting reflections for further research and public policies, specifically for Argentina and Brazil.

Keywords: Actors, Argentina, Brazil, deaths, soccer, violence.

\section{INTRODUÇÃO}

Compreender as múltiplas dimensões da violência em relação ao futebol pode ser uma tarefa complexa. Até maio de 2019, a lista de vítimas graves identificadas na Argentina ascendeu a 332 casos 1 . As vítimas relatam uma média que, desde 1922, resultou em três mortes por ano em quase um século. Além disso, a média anual de nove mortes de torcedores durante os últimos dez anos é maior do que a chamada "idade de ouro" do hooliganismo na Inglaterra, onde a estimativa aproximada dava seis torcedores mortos por ano, entre 1974 a 1989 (HOBBS; ROBIN, 1991: 553). Isto constitui uma razão importante para continuar a estudar este assunto no momento e poder comparar o cenário argentino com diferentes realidades, considerando que alguns registros dão conta de 304 mortes entre 1988 e 2016 no Brasi12, sendo 145 fatalidades apenas entre 2009 e 20173 . O problema da violência no mundo do futebol tem sido objeto de muitas pesquisas acadêmicas. Na Europa, o acervo possui uma história de várias décadas na tentativa de interpreção do hooliganismo (ARMSTRONG; HARRY, 1991; BRAUN; VLIEGENTHART, 2008; COMERON, 2002; DUNNING; MURPHY; WILLIAMS, 1986; EHREMBERG, 1991; INGHAM, 1978; MARSH, 1978; MIGNON, 1998; READHEAD, 1991; SPAAIJ, 2006; TAYLOR, 1971; WALGRAVE; LIMBERGEN, 1998; WILLIAMS; DUNNING; MURPHY, 1984, entre vários outros professores). No Brasil, a história da violência e o futebol, cuja enfâse são as torcidas organizadas, envolve também

\footnotetext{
${ }^{1}$ Lista das mortes no site da ONG Salvemos al Fútbol: http://salvemosalfutbol. org/lista-de-victimas-de-incidentes-de-violencia-en-el-futbol/ (acesso o 31.05.2019).

${ }^{2}$ https://www.lance.com.br/futebol-nacional/absurdo-futebol-brasileirochega-300-mortes-por-intolerancia-entre-torcedores.html (acesso o 31.05.2019).

${ }^{3}$ https://www.uol/esporte/especiais/especial-violencia-torcedores. htm\#imagem-1 (acesso o 31.05.2019).
}

uma série de trabalhos na sequência (MURAD 2013; 2017; HOLLANDA, 2014; 2017; TEIXEIRA; 2004; ZALUAR; MONTEIRO, 2003, por exemplo).

Na Argentina, o trabalho do sociólogo Amílcar Romero $(1985,1986,1994)$ foi o pioneiro na análise da violência para o período compreendido entre 1958 e 1983. O futebol (fútbol) é um dos principais componentes da identidade nacional da Argentina (ARCHETTI, 1999), capaz de deslocar multidões e atrair atenção política desde o início do século XX (DUQUE; CROLLEY, 2001; FRYDEMBERG, 2012; LEVINSKY, 2016; PALOMINO; SCHER, 1988). O futebol é lar das mais criativas coreografias e culturas de torcedores na Argentina, mas a violência e as mortes têm, no entanto, periodicamente, impactado o cenário. O antropólogo Archetti, em coautoria com o sociólogo Romero (1994: 39), sublinharam o fato que a junção de violência com a morte pode refletir processos sociais além dos limites de futebol. Suas análises, que constituiram as bases para posteriores pesquisas na Argentina, detalharam vários fatores: repressão policial "cega"; violência entre hinchas (torcedores) organizados; o destino de vítimas inocentes, a impunidade e as complexas relações com o poder institucional, no âmbito do futebol e na política nacional. A situação não mudou durante as últimas décadas do século XX e o início do novo milênio. Portanto, o problema levou de fato a vários projetos sociais de investigação, por um lado, e medidas de políticas públicas, por outro. Todas elas pensadas para "resolver" o "mal" argentino4 (GARRIGA, 2013; GODIO; ULIANA, 2016; SUSTAS, 2013). O número significativo de estudos provou o papel da violência para a construção de identidades masculinas, assim como também a sua utilização como recurso para

\footnotetext{
${ }^{4} \mathrm{Na}$ época dos hooligans, a mesma interpretação era feita pelos meios de comunicação, que chamavam o problema como a doença britânica (the british disease), (DUNNING, 2000).
} 
negociar diversos interesses (ALABARCES, 2013). Por sua vez, as respostas públicas foram reforçando o paradigma da segurança (ULIANA; GODIO, 2013). No entanto, os diagnósticos institucionais têm, em grande parte, omitido a análise sobre as condições precárias que ocorrem nos jogos e as modalidades e confrontos estimuladas pelas forças de segurança (ARAGÓN, 2017; SAIN; RODRÍGUEZ, 2014). Já nestes dois pontos principais podemos encontrar, talvez, alguns paralelos com os cénarios locais no Brasil, os quais podem ser comparados com o caso da Argentina.

A única informação (on-line) sobre tais incidentes na Argentina vem dos esforços da organização não-governamental (ONG) "Salvemos al Fútbol" (Salvemos), que continuou o trabalho de Amílcar Romero (SEGURA; MURZI; NASSAR, 2018). Em 2006, a ONG ganhou vida com o objetivo de denunciar um fato que tinha sido pessoalmente vivido pela sua fundadora, Mónica Nizzardo (NIZZARDO; BERGÉS, 2015). Em 2004, a sede do clube Atlanta ( $3^{\text {a }}$ divisão) foi visitada por um dos líderes da "Barra", isto pode ser traduzido como o grupo "radical", o que seriam as "organizadas" no Brasil. Em seu "protocolo" de visita, o líder pediu de forma agressiva para ver o presidente do clube. Ao não obter a resposta que ele queria, a pessoa, em seguida, destruiu computadores e quebrou janelas com uma barra de ferro. $\mathrm{O}$ caso foi a julgamento e a Justiça o isentou de qualquer pena, argumentando que não havia nenhuma razão para dar-lhe uma sentença condenatória. Para combater as ameaças sofridas, a fundadora da Salvemos fez vários apelos na mídia. Depois, ela recebeu chamadas de familiares de vítimas, em particular de outra mulher, Liliana Suárez, fundadora da FAVIFA (Familiares das vítimas de Violência no Futebol da Argentina), mãe de Daniel, um garoto de 18 anos morto em uma emboscada entre barras rivais argentinas na Copa América de 1995, no Uruguai (CHAPIETTA, 2015: 55). A Salvemos, desde então, tem fornecido apoio legal para vítimas (MURZI; SEGURA, 2014), assim como emitido comunicados à imprensa com uma série de relatórios e informações públicas via seu site e redes sociais. Esses esforços têm também estimulado a construção de pontes com o trabalho acadêmico (MURZI; ULIANA; SUSTAS, 2015; SEGURA; MURZI, 2015; MURZI; SEGURA, 2018). Nossas perguntas para este debate são as seguintes: quais são as formas adotadas pelos episódios de violência trágicos acontecidos entre os anos 2006 e 2018 na Argentina? Quais são os perfis "chaves" nesse contexto? Nesse sentido, pretendemos sugerir alguns paralelos compartivos com o Brasil e gerar alguns apontamentos a partir de uma pesquisa em andamento na cidade de Goiânia entre 2017 e 2019. Pedimos licença ao leitor para primeiro nos situarmos na revisão dos estudos no campo (BOURDIEU, 1981) argentino.

\section{OS ESTUDOS SOBRE VIOLÊNCIA E FUTEBOL NA ARGENTINA}

É claro que o futebol argentino se caracteriza pelo fervor das torcidas, chamadas de "hinchadas" e seus membros militantes de "hinchas" (ARCHETTI, 1985). Tradicionalmente, há inclusive duas principais categorias de espectadores: aqueles que permanecem sentados nas plateias e aqueles que estão em conjunto nas arquibancadas (la popular) do estádio. É neste último setor que os torcedores organizados são encontrados, ou seja, torcedores militantes que proporcionam apoio permanente: torcedores organizados (ou no termo nativo usado na Argentina: as barras). Porém, as barras consistem em grupos que controlam mais do que a estética das arquibancadas. Seus perfis foram evoluindo nas últimas décadas. A imprensa nomeou desde a década de 1950 os grupos organizados como barras bravas (CONDE, 2005), onde o termo "bravas" indicava, mais do que qualquer coisa, que eles eram perigosos, tanto para a imprensa quanto para o Estado...e para o resto do público que frequentava os estádios (MURZI, 2019). Seus membros normalmente descrevem-se como $\mathrm{La}$ Barra (GARRIGA, 2006; TADDEI, 2016), que é o termo nativo que nós vamos usar aqui e não aquele que a impressa instalou (barras bravas). Embora não haja uma definição unânime em torno destes termos, quando se fala de "barras" se faz referência, de fato, a grupos organizados de torcedores ativos que, através do seu jeito fervoroso de torcer, podem também usasr sua capacidade para gerar e administrar atos de violência. Ao mesmo tempo, as barras possuem relações instáveis com atores do mundo do futebol assim como com outros de diversos canais sociais, econômicos e políticos (ALABARCES, 2004; MURZI, 2019; SEGURA; MURZI; NASSAR, 2018). 
No entanto, as famosas "barras" não compreendem grupos homogêneos, uma vez que são frequentemente divididas em facções que lutam pelo controle do espaço, e do poder envolvido nesse campo em termos da terminologia sociológica de Pierre Bourdieu (1981). Mas, será que as "barras" são o único "ator" que produz violência relacionada com o futebol? Uma pergunta que tem o mesmo valor quando se faz a respeito das torcidas organizadas no Brasil.

Confusões entre hinchas e agressões voltadas para os jogadores e árbitros na Argentina foram observadas já desde as primeiras décadas do século XX (DUQUE; CROLLEY, 2001; FRYDEMBERG, 2012). Assim, duas mortes foram registradas ${ }^{5} \mathrm{em}$ 1922. Em 1924, um incidente em Montevidéu durante a Copa Sul-americana terminou com uma outra morte, quando um argentino assassinou um torcedor uruguaio após uma forte discussão (BARNADE; IGLESIAS, 2006). Em 1939, a brutal repressão policial no estádio do Lanús terminou com dois torcedores mortos. Cinco anos mais tarde, o "episódio do portão 11 " no estádio do River Plate deixou sete mortos por asfixia e vários outros feridos. Posteriormente, devido mais uma vez à desmedida repressão policial, houve mais vítimas em 1955 e 1958. Em 1959, um colapso de uma arquibancada no estádio do Estudiantes fez com que dois espectadores pagarem o preço com suas vidas. Amílcar Romero (1985) atribuiu o aumento da violência no futebol no final da década de 1950 devido ao contexto político. Em 1955 um golpe de Estado contra o Presidente Juan Domingo Perón teve lugar e o partido peronista foi proibido por muitos anos. Foi nesse ambiente tenso que o futebol, enquanto fenômeno de massas, tornou-se também um espaço para confrontos (LEVINSKY, 2016). Entre 1958 e 1983, o número de feridos alcançou aproximadamente 4.000 pessoas e os presos, ou detidos, excedeu os 5.000 (ROMERO, 1985: 10). A esse respeito, Archetti e Romero identificaram diferentes cenários de mortes vínculadas ao futebol. O primeiro foi ligado a brutal repressão da polícia: Alberto Linker (18 anos) perdeu sua vida no estádio do Velez em 1958 (ARCHETTI; ROMERO, 1994: 16). O segundo caso envolveu a intolerância entre os hinchas (torcedores) rivais. Em 1967, Héctor Souto (15 anos de idade) sofreu a infelicidade de defender

\footnotetext{
${ }^{5}$ Ver a lista de mortes no site da ONG: http://salvemosalfutbol.org/
}

um amigo que celebrou um gol do Racing Club de Avellaneda em um lugar "errado" do estádio, onde o núcleo duro dos torcedores do clube Huracán estava. Este episódio marcou uma nova era, dado que os espectadores pararam de circular no interior dos estádios (ARCHETTI; ROMERO, 1994: 26). Entre "parênteses", o ano de 1968 teve a maior tragédia do futebol argentino, na Porta 12 no estádio do River Plate, onde 71 torcedores do Boca Juniors morreram depois de ser esmagados contra um portão fechado na tentativa de saída do estádio. Várias investigações indicaram que os torcedores tiveram momentos de tensão anteriores com a polícia (ALABARCES, 2004; ARCHETTI; ROMERO, 1994). O terceiro perfil esteve ligado a perseguição política. Em um jogo na cidade de La Plata em 1976, a polícia atirou contra torcedores do Huracán, considerados pela ditadura como extremistas de esquerda (ROMERO, 1986: 74). O quarto cenário foi o resultado de um confronto planejado entre torcedores organizados do Boca Juniors e os do Quilmes, com duas mortes, uma para cada "lado" em 1983 (ARCHETTI; ROMERO, 1994: 33). Durante as décadas seguintes, os cientistas sociais, muitos deles inspirados por Archetti e Romero, continuaram a propor abordagens sob diferentes ângulos.

Alguns acadêmicos sublinharam os significados simbólicos dos confrontos durante a década de 1990. Isso, no jargão "nativo" (GARRIGA, 2006), veio sob a bandeira de possuir "aguante", isto é, uma forma de enfrentar e resistir frente aos "inimigos" (ALABARCES, 2004), numa forma de agressões ritualizadas, da mesma maneira que o hooliganismo tinha sido interpretado na Inglaterra duante a década de 1970 (MARSH, 1978). Uma série de estudos na Argentina provaram como o futebol podia ser visto como um campo de batalhas fornecedor de prestígio para os "vencedores" (ARAGÓN, 2007; GARRIGA, 2006). Os roubos de "troféus" - bandeiras, faixas e tambores - mantiveram parte deste folclore por muitos anos (MOREIRA, 2005). Nessa tônica, a construção de identidades masculinas tem reproduzido práticas de "virilidade" (CABRERA, 2013; CZESLI, 2013; GAFFNEY, 2009; GIL, 2007). Por outro lado, o "carnaval" do futebol na Argentina (ARCHETTI, 1992) tem sido muitas vezes imitado em outros países, desde os vizinhos até no México, Espanha ou mesmo Japão (CARRIÓN, 2014; CASTRO, 2013; 
HOLLANDA, 2017; SEGURA, 2013). Isso pode ser explicado pelo fervor e pela capacidade das hinchadas para produzir vários cânticos originais, denominados na Argentina como "cantitos" (GANDARA, 1997; PARRISH; NAURIGHT, 2013, BUNDIO, 2016), o uso de instrumentos musicais, as coloridas decorações das arquibancadas e deslocamento dos grupos para os estádios. No entanto, as ameaças mortais também foram sendo incorporadas explicitamente desde os anos 1980 (BUNDIO, 2016) em muitos "cantitos".

Mas a maior fonte de "aguante", neste microcosmo (WIEVORKA, 1977), tem sido as batalhas contra a polícia (ALABARCES, 2004; ARAGÓN, 2007). Os confrontos têm alimentado códigos recíprocos, até o ponto em que a polícia é percebida como um terceiro-inimigo, o maior de todos (GALVANI; PALMA, 2005). Aí, existe um claro paralelo que pode ser traçado com a ideologia dos hooligans britânicos e seus confrontos frequentes com a polícia entre as décadas de 1960 e 1990 (KERR, 1994). No que diz respeito ao Estado Argentino, várias leis e normas têm reforçado medidas repressivas desde 1985, quando surgiu a primeira lei para combater as "barras-bravas" (MURZI 2019; SUSTAS, 2013). O leitor pode conferir as estatísticas coletadas pela ONG Salvemos al Fútbol, disponíveis no seu site, as quais detalham que $22 \%$ das mortes entre 1966 e 2012 foram devido à repressão policial (MURZI; ULIANA; SUSTAS, 2015), um número assustador no que se refere à "prevenção" da violência. Isto significa, em outros termos, que a reação da Polícia tem sido um fator que aumentou a violência e as mortes. Esta mesma conclusão foi justamente destacada no famoso relatório Taylor na Inglaterra, assim como em outras pesquisas empíricas feitas na Europa (STOTT; ADANG; LIVINSTONG; SCHREIBER, 2008). Aqui, os paralelos com os cenários brasileiros e seus contextos regionais teriam muito para analisar sobre a forma de atuar da PM e os corpos de segurança pública. Na Inglaterra, a gestão da polícia mudou completamente após das reformas do futebol inglês nos anos 1990 (WARD; WILLAMS, 2009: 341). Na Argentina, os perímetros de segurança ao redor dos estádios foram concebidos como parte de verdadeiras operações militares para separar torcedores rivais desde final dos 1960 até o ano 2013 (TADDEI, 2016; ULIANA; GODIO, 2013). Porém, a partir da década de 1990 os grupos e indivíduos pertencentes às barras, sobretudo suas lideranças, aprenderam a negociar acordos com as polícia locais a fim de gerar arranjos e estabelecer relações com benefícios para ambas as partes (BERGÉS, 2015). Com essa descrição histórica, podemos, agora, analisar algumas novas situações no século XXI no cenário argentino.

\section{DISPUTAS INTERNAS NA ARGENTINA NO SÉCULO XXI}

Diferentes estudos já demostraram o fato dos cartolas e funcionários dos clubes, além de alguns políticos bem conhecidos na Argentina (BERGÉS, 2015; DEL FRADE, 2008), terem alimentado relações clientelistas com grupos de barras, até mesmo para o apoio para atingir a presidência de algum clube. Cabe lembrar que na maioria dos clubes argentinos a eleição das autoridades se faz via votação dos sócios dos clubes. Os grupos de barras tem sido, por vezes, "solicitados" para a intimidação de potenciais adversários (DUQUE; CROLLEY, 2001; MOREIRA, 2012; SAIN; RODRÍGUEZ, 2014). Os estudos mais recentes começaram a reparar que nem todas as dimensões do "aguante" se mantiveram ao nível do ritual masculino. Os grupos passaram a agir como redes verdadeiramente complexas, instáveis e fragmentadas nos seus interesses e vínculos (BUNDIO, 2013), com uma gama de conexões chaves (D'ANGELO, 2012), dotadas de instintos de sobrevivência. Nesse sentido, um novo problema instalou-se na década de 2000-2010: as mortes ligadas aos grupos da mesma arquibancada. Pode-se observar que entre os anos 2000 e 2012, das 77 mortes, $36 \%$ foram causados por lutas internas de grupos de torcedores do mesmo clube (SEGURA, 2013: 33). Uma das principais razões pode ser atribuída às disputas pelo poder que envolve o controle de uma barra (MURZI, 2011), assim como os interesses individualistas dos líderes de tais grupos, inclusive, alguns em harmonia com tendências neoliberais do país e dos dirigentes de clubes que têm, aos poucos, permeado a cultura das arquibancadas, a partir dos níveis de corrupção nas esferas políticas e sociais para o mundo de futebol (ARAGÓN, 2017). Por conseguinte, estas brigas podem ser interpretadas, em termos de Bourdieu (1981), como lutas para controlar um "campo", ou se o leitor quiser interpretá-lo de forma mais sofisticada como um sub-campo dentro de um campo maior 
numa leitura a partir do sociólogo francês. Isso ocorre tanto em grande clubes, tais como Boca Juniors, River Plate, Racing de Avellaneda, San Lorenzo ou Independiente, como em clubes de tamanho médio em termos de torcedores, mas também em clubes de baixa classificação nos torneios argentinos.

Além desse problema, o qual não pode ser negado, a imprensa constitui também outro ator crucial, uma vez que, embora alegue falar sobre "os fatos", a "violência do futebol" também é usada como uma mercadoria que vende relatos, gera audiência na TV, assim como outros impactos midiáticos (SZLIFMAN, 2010), como são hoje as repercussões nas redes sociais. A mídia hegemônica, na Argentina, uma situação que merece uma comparação séria com a mídia dominante no Brasil a respeito das torcidas organizadas, tende a salientar o discurso único: as "barras-bravas" representam o núcleo do problema (MURZI, 2019). No entanto, os cientistas sociais têm sugerido uma interpretação mais ampla da prevalecente atmosfera de violência no mundo do futebol (SODO, 2013). A hipótese proposta pelos pesquisadores Diego Murzi, Belen Nassar e o autor principal deste artigo (2018) para analisar o cenário argentino entre 2006 e 2018 indica que, longe de ter sido contida, novos quadros de mortes e transtornos marcaram a direção do futebol na Argentina. A partir daí, quatro hipóteses específicas foram desdobradas, as quais podem ser, cada uma delas, comparadas com os cenários brasileiros regionais segundo seus problemas e desafios locais:

1. Houve um aumento das fontes de renda ao redor das barras e, portanto, das disputas internas nos diferentes grupos de uma hinchada (barras). 2. As políticas públicas destinadas a reprimir a violência e instalar o modelo de torcidas únicas tem contribuído para exacerbar os conflitos internos nas barras argentinas. 3. Ao contrário das décadas anteriores, quando os problemas aconteciam dentro ou ao redor dos estádios, um número crescente de episódios estão ocorrendo longe dos recintos do futebol. 4. Os incidentes coletivos que envolvem atores não-membros das barras, muitas vezes ocorrem devido a divergências sobre os resultados dos jogos, adicionando mais ingredientes para a atmosfera de violência geral, especialmente nas ligas "inferiores" e nas categorias de base dos clubes.

\section{QUESTÕES DE METODOLOGIA NO ESTUDO DOS CASOS}

Os dados que aqui são colocados provêm da lista de mortes e incidentes relacionados com o futebol na Argentina que a ONG Salvemos al Fútbol construiu a partir do trabalho iniciado pelo sociólogo Amílcar Romero (1986) até 1994. Depois de 10 anos de existência, a ONG - da qual o autor principal deste texto faz parte desde 2007 - decidiu, em 2016, fazer um banco de dados para classificar esses arquivos e produzir uma abordagem mais sistemática (SEGURA; MURZI; NASSAR, 2018). É importante esclarecer que, por falta de capacidade metodólogica, este trabalho não considera a violência verbal dos cânticos nas arquibancadas que incitam à morte do "inimigo", à degradação e as discriminações, todos eles fatores que deveriam ser incluídos, também, nas categorias de violência no futebol.

A pesquisa sistematizada inicialmente entre três membros da ONG compreendeu específicamente os anos entre 2006 até 2017 e revelou um total de 651 episódios identificados que envolveram agressões físicas entre diferentes atores. Desse universo, 98 casos terminaram em mortes, o que representou um total de $15 \%$ da amostra, e uma média de 9 mortes por ano. O desdobramento dos dados indicou que, dos 651 episódios, 153 foram agressões de torcedores de todo tipo - isto é, não únicamente os notórios membros das barras - destinadas contra jogadores de futebol, treinadores, funcionários ou árbitros: em termos porcentuais essa modalidade de violência representou um $27 \%$ do total. No entanto, as barrasbravas foram diretamente responsáveis (segundo a imprensa) em $63 \%$ dos casos identificados, seja por lutas entre torcedores rivais tradicionais, brigas com a polícia, ou mesmo entre grupos de diferentes facções como veremos mais a frente. Isto pode indicar que, apesar das barras serem realmente um ator relevante na violência no futebol, existe na Argentina um total de $37 \%$ de episódios de diferentes atos (agressões físicas para nossos objetivos de pesquisa) que são ocasionados por outros atores (não-membros das barras): torcedores "comuns", polícia, jogadores e, inclusive, os próprios dirigentes em algumas ocasiões. Sem incluir a violência verbal, às vezes homofobica, de parte de representantes da mídia (um objeto que merece uma série de artigos na Argentina), assim 
como no Brasil e outros contextos. No caso goiano, por exemplo, a imprensa esportiva apresenta, além de discursos, "piadas" e atitudes homofóbicas, toda uma estrutura de silenciamento da homossexualidade no futebol, por ser considerado um assunto não relevante para coberturas jornalísticas (FERNANDES, 2019). Mas o que é realmente característico do caso argentino é o crescimento de lutas nos últimos 10 anos entre grupos de um mesmo clube, as quais atingiram $24 \%$ entre as agressões identificadas para os anos entre 2006 e 2018 (MURZI; SEGURA, 2018: 55). Logicamente, então, esse tipo de conflito foi a principal causa de mortes $(51 \%)$. A violência entre torcedores rivais, aquela que era a principal preocupação em décadas anteriores, que na maioria dos países europeus tem continuado a ser o problema mais relevante (DUNNING, 2000; GINHOUX, 2016; GLORIZOVA, 2016; TSOUKALA, 2010), da mesma forma do que tem acontecido no Brasil (MURAD, 2017; MURAD, 2013), agora aparece em um estágio secundário na Argentina. Ela representa 19\% dos incidentes, mas todavia uma alta porcentagem das mortes: $32 \%$.

No que se refere aos controntos entre torcedores e policiais na Argentina, $14 \%$ dos fatos identificados entram nessa categoria (MURZI; SEGURA, 2019: 56). Além disso, outros tipos de modalidades, embora com menor representação, também constituem formas de violência: destruição de patrimônio (ou seja, carros, lojas ou as próprias instalações dos clubes); agressões entre os "protagonistas" do jogo, isto é, jogadores de futebol envolvidos em batalhas; assim como "trágicos" acidentes, quando os torcedores podem ter caído das arquibancadas, de um trem ou de um ônibus. Seguindo assim com as considerações metodológicsa que este trabalho destaca, o trabalho da ONG Salvemos continuou com o levantamento de dados a partir do escândalo da final da Taça Libertadores de 2018, após as pedradas que o ônibus dos jogadores do Boca Juniors recebeu por parte de torcedores do River Plate (não-membros da barra-brava). Contudo, no ano de 2018, N:81 episódios de violências foram indentificados pelo levatamento habitual e anual da ONG. A partir desses incidentes, 10 mortes (12\%) tiveram relação com brigas por conta do futebol numa escala nacional. Porém, a conclusão foi que só uma das mortes aconteceu no perimêtro de um estádio, no jogo da final da Copa Argentina entre Rosario Central e Gimnasia Esgrima de la Plata, no estádio Malvinas em Mendoza ${ }^{6}$. As estatísticas totais levantadas pela ONG têm indicado os seguintes números:

Tabela 1: Lista de mortes na Argentina

\begin{tabular}{c|c}
\hline Anos & Quantidade de mortes identificadas \\
\hline $1922-2018$ & 332 \\
\hline
\end{tabular}

Fonte: Salvemos al Fútbol.

Tabela 2: mortes na Argentina entre 2006 e 2018

\begin{tabular}{c|c}
\hline $\begin{array}{c}\text { Quantidade de mortes } \\
\text { identificadas }\end{array}$ & Média de mortes por ano \\
\hline 110 & 9 \\
\hline
\end{tabular}

Fonte: (MURZI; SEGURA, 2018) e Salvemos al Fútbol.

Essas estatísticas podem ser comparadas com as mortes identificadas no Brasil por diferentes veículos de imprensa, assim como pelo sociólogo Mauricio Murad:

Tabela 3: Mortes e futebol no Brasil

\begin{tabular}{c|c}
\hline Anos & Quantidade de mortes identificadas \\
\hline $1998-2017$ & 304 \\
\hline
\end{tabular}

Fonte: Lance (2016) e Murad (2017).

A média entre 1998 e 2017 é muito similar a da Argentina, isto é, 9 mortes por ano. No entanto, entre os anos 2009 e 2017, o número de tragédias parece ter tido um aumento:

Tabela 4: Mortes e futebol no Brasil entre 2009 e 2017

\begin{tabular}{c|c}
\hline $\begin{array}{c}\text { Quantidade de mortes } \\
\text { identificadas }\end{array}$ & Média de mortes por ano \\
\hline 145 & 16 \\
\hline
\end{tabular}

Fonte: Guilherme Costa (UOL, Brasil) com dados Murad (2017).

Ora, a população estimada para Argentina era, para o ano 2018, de aproximadamente 45 milhões de habitantes, isto significa que a média de 9 mortes por

\footnotetext{
${ }^{6}$ Dados coletados por Belén Nassar para as estadísticas internas da ONG (em preparação para um Relátorio, El Plan Bergés 2019 (Presidente da ONG) sobre o diagnóstico da violência no futebol da Argentina e o paradigma da segurança pública dos últimos 35 anos.
} 
ano, por conta ou em relação ao futebol, daria um ratio de $\mathbf{0 . 0 0 0 0 0 0 2}(9 / 45,000,000)$ entre 2006 e 2017 . No Brasil, esse ratio daria $\mathbf{0 . 0 0 0 0 0 0 0 7 6}$ (16/208,000,000 aprox) entre 2009 e 2017. Se só considerarmos as mortes (304) por estados entre 1988 e 2016 no solo brasileiro, o "ranking" dos estados mais violentos em relação ao futebol mostra esses número:

Tabela 5: Estados mais violêntos em relação ao futebol entre 1988 e 2016

\begin{tabular}{l|l|l}
\hline Estados & $\begin{array}{l}\text { Quantidade } \\
\text { de mortes } \\
\text { identificadas }\end{array}$ & $\begin{array}{l}\text { Média de mortes } \\
\text { por ano }\end{array}$ \\
\hline São Paulo & 50 & $(1.8): 2$ mortes \\
\hline Rio Grande do Norte & 43 & $\begin{array}{l}(1.4): \text { uma ou duas } \\
\text { por ano }\end{array}$ \\
\hline Rio de Janeiro & 32 & 1 morte por ano \\
\hline Goiás & 30 & $\begin{array}{l}1 \text { morte cada } 2 \\
\text { anos aprox. }\end{array}$ \\
\hline
\end{tabular}

Fonte: Lance $(2016)^{7}$.

O Ceará segue na lista de registros com 27 mortes e o Pará com 20 fatalidades (FERNANDES, 2017: 49). Como o leitor pode perceber, os cenários nacionais argentino e brasileiro apresentam números similares em termos absolutos. No entanto, as diferenças regionais e contextuais devem ser apontadas em qualquer análise. Na Argentina, as mortes acontecem principalmente na área urbana da Cidade de Buenos Aires e sua periferia, chamada de "Grande Buenos Aires", como as cidades de Rosario e Santa Fe, somadas a alguns casos mais pontuais em outros estados (províncias) tais como Córboda, Tucumán ou Jujuy (MURZI; SEGURA, 2018). No que se refere a pesquisas espefícias, os autores do artigo estão realizando um levantamento desde agosto 2017 no estado de Goiás, em particular na zona metropolitana de Goiânia incluindo as cidades de Aparecida, Senador Canedo e até Trindade. Sendo que os dados apresentados na Tabela anterior mostram 30 mortes até 2016, devemos adicionar pelo menos 9 mortes acontecidas entre 2018 e 2019 para essa área ao redor de Goiânia. Alguns detalhes sobre situações

\footnotetext{
${ }^{7}$ https://www.lance.com.br/futebol-nacional/potiguares-paulistas-goianoscearenses-sao-torcedores-que-mais-morrem-matam-brasil.html (acesso o 1 de junho de 2016).
}

espefícias serão, nesse sentido, comentadas nas próximas seções. Porém, de quê tipo de incidentes estamos falando? Quê tipo de lógicas, interesses e "atores" estão envolvidos? Devemos focarmos só nas mortes? Justamente para não permanecer somente no quadro das mortes e poder refletir sobre diferentes naturezas de agressões no futebol, todas elas geradoras de atmosferas de violência (SODO, 2013), iremos propor uma tipologia baseada na Argentina (SEGURA; MURZI; NASSAR, 2018), para tentar, num segundo plano, discernir alguns paralelos e diferenças para os diversos contextos que existem no futebol do Brasil.

\section{LUTAS ENTRE PARES: UMA TENDÊNCIA SÓ NA ARGENTINA?}

O caso da barra do River Plate, nomeada como os Bêbados (Los Borrachos del Tablón) pode ilustrar as crescentes lutas internas pelo controle das hinchadas na Argentina. Durante a Copa do Mundo de 2006 da FIFA, as principais lideranças dos Borrachos foram observadas na televisão incentivando a seleção nas arquibancadas. Esse fenômeno acontece desde a década de 1980, isto é, os chefes das barras têm tido a tradição de viajar para as Copas do Mundo, semelhante aos padrões dos hooligans ingleses (WILLIAMS; DUNNING; MURPHY, 1984) ${ }^{8}$. Um ano depois, em 2007, um conhecido membro da Barra do River, Gonzalo Acro, foi assassinado quando estava saindo da sua academia. Depois de sua morte, a competição para o comando da Barra começou a ocorrer como um expandido padrão de disputas em diversas barras argentinas (MURZI, 2019: 175). As grandes barras, e em alguns sentidos as menores também (nos seus contextos locais), representam uma fonte de contatos, posições, rendas por operações e serviços, assim como uma estrutura de empresas clandestinas. Por exemplo, ser membro de uma barra pode ser útil para garantir conexões informais, mas também alguns empregos formais, seja em sindicatos, seja em prefeituras (GARRIGA, 2006; MOREIRA, 2012). Da mesma forma, os papéis, em termos da sociologia de Goffman (1959), que os membros "destacados" de algumas barras têm conseguido "arrumar" vão desde motoristas de políticos ou presidentes de clubes,

\footnotetext{
${ }^{8}$ A diferença entre as barras argentinas e os hooligans britânicos seja talvez que muitas vezes as barras bravas, em particular entre 1982 e 2010 foram apoiadas pelos próprios clubes e até pelos governos em turno.
} 
guarda-costas em eventos e shows, até pessoal de segurança em manifestações políticas e sindicais. Em relação a seus próprios business, as barras, em arranjos com a polícia, assumiram durante décadas o controle dos estacionamentos adjacentes ao estádios, inclusive nos espaços públicos das ruas. Através da intimidação, muitas barras foram assumindo também, em alguns casos dentro dos estádios, a venda de alimentos, assim como a comercialização de diversos narcóticos (GARRIGA; MURZI; ROSAS, 2017). À respeito deste último aspecto, foi frequente observar nos estádios de Goiânia, em particular no Serra Dourada durante a pesquisa em andamento ${ }^{9}$, a venda de drogas nas arquibancadas.

Ora, na Argentina, figuras como o Gonzalo Acro demostraram que várias líderanças não são precisamente figuras marginais na sociedade. Acro, por exemplo, pertencia a um grupo que ocupava espaços do clube, piscinas, academias, campos de vôlei, restaurantes e inclusive alguns deles estavam sobe a folha de pagamento de sálarios na presidência de José María Aguilar (CARROZA, 2015). Várias lideranças dos Borrachos, na época do assassinato de Acro, em particular o grupo vínculado aos sálarios do clube, costumavam se vestir com estilo e etiqueta, tal como Hobbs e Robin (1991) descreveram ser comum entre líderes de renome no periodo dourado dos hooligans na Inglaterra no final dos anos 1980. A causa do assassinato apontou fortes disputas entre diferentes facções dos Borrachos (Murzi, 2011). As agressões continuaram, como esperado, após a morte de Acro em diferentes cenários. Em 2008, duas facções da barra se enfrentaram no estádio do Velez. Em 2010, outro torcedor do River Plate, Jonathan Waldmeier, morreu depois de um tiro executado por outra facção em seu caminho de ônibus para o estádio.

Na realidade Argentina (MURZI, 2019), a resposta do clubes e das forças de ordem tenderam a reconhecer a facção capaz de se impor pela presença ou pela negociação de acordos com os clubes e (tradicionalmente com a polícia), criando, desta maneira, grupos estabelecidos nas barras e grupos marginas excluídos, em termos da sociologia de Norbert Elias (1997). Esta situação tem sido objeto

\footnotetext{
${ }^{9}$ Pesquisa liderada pelo autor principal do artigo junto os alunos que participaram nas disciplinas da Pós-Graduação em Sociologia: Luiz Fernandes, Ricardo Junqueira e Flávia Alchuffi, Vitor Gomes, Thaissa Netto, Thiago Almeida e Guilherme Augusto.
}

de múltiplas disputas, onde os grupos estabelecidos procuram preservar o poder e, aqueles excluídos, a re-conquista do espaço perdido ou pretendido. Como um exemplo, a cafeteria do clube River Plate foi tomada em um ataque por uma facção dissidente em 2014, com a intenção de "ensinar uma lição" para a liderança "oficial” dos Borrachos na época. A distribuição de benefícios, bem como o prestígio de ocupar um lugar central no estádio, estabelece uma correlação entre as disputas internas nas barras que têm deixado várias mortes nos últimos 10 anos. $\mathrm{O}$ ano 2010 foi particularmente trágico, com 10 torcedores mortos como resultado destas brigas internas. Outro caso triste foi o assassinato do jornalista militante do Racing Club de Avellaneda, Nicolas Pacheco, que foi encontrado morto na piscina de uma das sedes do clube em janeiro de 2013. Na cena do crime estiveram presentes membros de uma facção aspirante para controlar a barra.

A partir da morte de um hincha (torcedor) membro da barra do Lanús, no estádio Único da cidade de la Plata, pela feroz repressão policial em junho de 2013, a resposta de política pública das autoridades provinciais foi a proibição de torcedores visitantes, com a expectativa de que isso poderia reduzir a violência no futebol. Esta questão deve ser analisada a sério no Brasil, onde a tendência nos jogos de clássicos com histórico de violência tem levado à política judicial da torcida única. Na Argentina, tal medida não levou em consideração o aumento dos confrontos entre facções do mesmo time. O escândalo, em maio de 2015, no jogo das oitavas da Copa Libertadores entre Boca Juniors e River Plate, apesar do fato de não haver torcedores visitantes, grupos dissidentes, pelo suposto intuito de não só de prejudicar os jogadores do River com spray de pimenta, levantaram a hipótese do ato ter sido uma provocação para outros grupos de torcedores estabelecidos no poder da Barra do Boca, La Doce. Cabe apontar que, depois disso, torcedores "comuns" nas plateias elegantes do estádio jogaram garrafas de água contra os jogadores do River, os quais se recusaram a continuar a partida. Em clubes menores com características mais suburbanas, a economia clandestina (Muriz, 2019), os laços políticos e as tensões nos bairros podem explicar muito sobre os conflitos entre facç̧ões. A lista inclui dramáticos episódios entre torcedores do Quilmes, Almirante Brown, Nueva Chicago, Ituizaingó, 
Berazategui, e o clube Antonio Guarani Franco, na província de Misiones, entre muitos outros exemplos. Também vale notar que algumas barras, antigamente inimigas, podem ter acordos para dividir mercados, como o controle do famoso Mercado de la Salada (na Grande Buenos Aires, distrito de Lomas de Zamora) entre grupos vínculados a Boca Juniors, Los Andes, Lanús, Temperley e mesmo River Plate), em conexão, claro, com autoridades políticas e policias. Todos estes elementos, podem dar a impressão para o leitor de língua portuguesa que as disputas são só produzidas pelas famosas barras bravas, segundo a visão e a ideologia da mídia dominante na Argentina (MORALES, 2015). No entanto, em abril de 2017, Emmanuel Balbo, um jovem torcedor do Belgrano de Córdoba, foi brutalmente agredido no estádio em um jogo com torcida única. Balbo teve uma discussão com outro torcedor por causa de conflitos relacionados com sua família, mas este último começou a acusar falsamente Balbo de ser fã do Talleres de Córdoba. Balbo foi jogado para o espaço vazio abaixo de um setor do estádio, sem nenhuma participação da Barra, morrendo mais tarde no hospital (SZILFMAN, 2019)10.

Mais uma vez, o leitor poderia até pensar que essas disputas estão longe de ser a principal tendência no Brasil. Porém, múltiplos exemplos podem ser enocontrados. Na cidade de Goiânia, a torcida do Vila Nova teve, durante anos recentes, duas facções se enfrentando, a Sangue Colorada e a atual e "tradicional" torcida organizada Esquadrão. Houve entre elas uma série de mortes, o que levou a Sangue Colorada a ser extinta. Em abril de 2019, houve um confronto entre torcedores do Palmeiras, que, se não deixou mortos, criou um alerta, assim como acontece entre outras várias torcidas no Brasil.

\section{CONFRONTOS CLÁSSICOS ENTRE TORCEDORES RIVAIS}

A morte de Marcelo Cejas, um torcedor militante (hincha), mas não membro da Barra do Tigre, que foi atingido por uma de pedra depois de um ataque da barra do Nueva Chicago em 2007, constitui uma ilustração do ódio e intolerância que muitas vezes

\footnotetext{
${ }^{10} \mathrm{https} / / /$ www.laizquierdadiario.com/Justicia-en-el-caso-Balbo (acesso o 7 de junho de 2019).
}

têm se expressado para os rivais considerados como inimigos. O jogo era a definição para a promoção para a Primera Divisão de uma equipe (Tigre) ou a sobrevivência do Chicago na divisão superior do futebol argentino. Este episódio marcou o início da proibição de visitantes para jogos no Nacional $B$ (segunda divisão). Durante aqueles anos de 2006, 2007 e 2008 houve vários confrontos nos derbies (clássicos) locais em várias províncias. Esses cenários são ainda, e em geral, os mais problemáticos no Brasil. Em 2008, nesses confrontos entre torcedores inimigos, o clásico porteño viu a morte de Rodrigo Silvera, um torcedor do Huracán, morto a tiros pela Barra do San Lorenzo, próximo ao estádio. Um hincha do Velez, Emanuel Alvarez, também foi morto da mesma forma quando os ônibus da hinchada iam para o estádio do San Lorenzo, porém, o que as investigações indicaram foi que o disparo partiu da sede social do clube Huracán, sendo estes três times inimigos em termos de territórios na cidade de Buenos Aires. Estas disputas envolvem, na prática, o combate e até a morte dos inimigos por questões de "honra" e "reputação" (ARAGÓN, 2007; GARRIGA, 2006; MOREIRA, 2005). Como o leitor pode imaginar, os hinchas organizados adotaram o hábito de resolver suas antigas disputas de combates físicos, "corpo a corpo", através de armas de fogo. Esta situação, que também é frequente em vários contextos do Brasil, por exemplo em Goiânia, onde entre 2018 e 2019 várias mortes entre torcedores da Força Jovem do Goiás e a Esquadrão do Vila Nova foram "resolvidas" aos tiros. Este tipo de mortes constitui uma faceta quase inédita no contexto europeu, onde a "honra" do hooligans se disputa pela dominação da batalha física (WILLIAMS; DUNNING, MURPHY, 1984; NEWSON, 2017).

Foi nesse sentido que a proibição do público visitante, o equivalente das torcidas únicas no Brasil, foi implementada como um almejado meio para evitar os distúrbios urbanos nos dias de jogos na Argentina em todas as categorias profissionais desde o ano 2013. No entanto, os embates ferozes nos bairros foram se intensificando entre torcidas rivais. A cidade de Rosario constitui um exemplo de repetidos confrontos entre torcedores do Newell's e do Rosario Central. A título de ilustração, um grupo de torcedores do Newell's foi atacado a tiros em dezembro de 2013 quando estava saindo da cidade logo depois de um 
jogo com torcida única por dois torcedores do Rosario numa motocicleta. Os torcedores Leonardo Boladian e Walter Palacio foram mortos, uma mulher e sua filha de sete anos foram seriamente feridas ${ }^{11}$. Diferentes tentativas para permitir ambas torcidas nos jogos desde o início de 2017 têm demostrado que a questão não se trata de só pedir para os torcedores não brigar, mas também de considerar a brutalidade policial como um fator de violência. Várias cenas de agressões da polícia contra torcedores foram identificadas nos levantamentos de fatos que realiza a ONG Salvemos (MURZI; SEGURA, 2018). Esta questão merece uma comparação mais detalhada com as diferentes Polícias Militares no Brasil e suas formas de lidar com os torcedores.

\section{CONFRONTOS COM A POLÍCIA: OUTRA FORMA DE VIOLÊNCIA}

Os confrontos entre hinchas e a polícia têm constituido um fato histórico no futebol da Argentina (ARCHETTI; ROMERO, 1994), assim como uma fonte de mortes até 2019, mesmo que a tendência tenha diminuído nos últimos 10 anos (MURZI; ULIANA; SUSTAS, 2015; MURZI; SEGURA, 2018). Desde a década de 1930, as formas de abordagens policias têm provocado frequentes agressões contra os torcedores. Basta, para o leitor, revisar os trabalhos já publicados por Alabarces (2004), Galvani e Palma (2005) ou do antropólogo brasileiro Renso Taddei (2016), que passou um ano na Argentina observando diferentes aspectos do futebol, entre eles como a gestão policial. Neste clima, os jogos de alto risco envolvem o pagamento de horas extras, assim como o desenvolvimento das mais sofisticadas operações de controle do público (ULIANA; GODIO, 2013). Cenários de brutalidade contra a polícia também têm marcado o histórico dos incidentes. Na localidade de Laferrere, cujo clube trânsita entre a terceira e a quarta divisão do futebol argentino, um grupo de policiais foi atacado em março de 2015, quando tentaram evitar que aproximadamente 200 torcedores do time entrassem no estádio sem ingressos. Dois policiais foram severamente feridos, até o ponto de ser necessário o resgate através de um helicóptero.

\footnotetext{
${ }^{11}$ A ONG Salvemos, através de seu presidente, Mariano Bergés, deu apoio legal para as vítimas. Um dos agressores, aquele que atirou, foi condenado em 2017 a 30 anos na prisão.
}

A gestão do Estado Argentino, colocada em prática após a eleição presidencial de 2015, se caracterizou por um programa nacional chamado Estádio Seguro, cujo príncipio foi realizar uma revista eletrônica dos torcedores e impedir o ingresso de qualquer pessoa com antecedentes penais (não unicamente no âmbito do futebol) e tentar "limpar" das arquibancadas os indíviduos indesejados para a "sociedade" do futebol (MURZI, 2019). Na juridição da província de Buenos Aires, a maior da Argentina, aquela que representa o maior número de deslocamento de torcedores a cada semana, foi também implementado um programa de "tolerância zero" para os grups de barras bravas, considerados pelo responsável da gestão como deliquentes a serem expulsos e interditados. Na realidade, a política resultou na proibição de vários grupos e, sobretudo, no maltrato geral dos torcedores pela polícia. Em termos de pesquisa acadêmica, muitas vezes é díficil esclarecer os fatos quando os excessos são cometidos pelos agentes do Estado, mais ainda quando a mídia corporativa não tende à reportá-los como episódios de violência contra os torcedores (SEGURA; MURZI; NASSAR, 2018: 11). Intuímos que a mesma dificuldade se apresenta para as pesquisas independentes realizadas no Brasil. Finalmene, existe um fator adicional que contribui para a criação de ambientes de violência: as agressões entre os protagonistas do jogo, o que inclui os incidentes que ocorrem nas categorias de base com bastante frequência.

\section{AGRESSÕES CONTRA E ENTRE OS PROTAGONISTAS DO JOGO}

As agressão contra jogadores e árbitros têm sido freqüentes no futebol da Argentina desde o início do século XX (FRYDEMBERG, 2012). A questão hoje é: quem executa tais atos? A resposta não é simples. Se analisarmos episódios recentes, nos deparamos com um cenário complexo de "atores" e de diversas situações. Em 2011, por exemplo, membros da Barra do River Plate entraram no campo de jogo em uma partida chave para evitar o rebaixamento do time com o objetivo de intimidar seus próprios jogadores. Uma semana mais tarde, membros do mesmo grupo tentou atacar o árbitro, quando o clube foi inevitavelmente rebaixado para a $2^{\text {a }}$ divisão (MURZI, 2011). Na verdade, vários jogadores de futebol e árbitros foram 
atacados durante estes anos de estudo e levantamentos da ONG Salvemos (2006 e 2018): a lista inclui mais de 35 clubes onde fatos desta natureza aconteceram. Javier Cantero, presidente do Independiente de Avellenada (2011-2014), que abertamente desafiou os interesses da Barra, foi constantemente ameaçado e, inclusive, agredido fisicamente (CANTERO, 2014). Em outubro de 2013, a presidente do clube Yupanqui ( $5^{\text {a }}$ divisão), Lilian Machado, teve que se esconder em um escritório e esperar a polícia chegar quando um grupo da Barra tentou atacá-la. Esse tipo de ameaças também têm afetado vários treinadores e jogadores. Como parte dos privilégios adquiridos pelas barras, qualquer ameaça para suas posições em seu campo de poder (BOURDIEU, 1981) pode levar a ameaças e agressões para defender suas posições. No entanto, como temos colocado ênfase desde o início, as barras não são os únicos atores na produção de violência. Em 2015, Matías Fritzler, jogador do Lanús, foi atacado por um torcedor "comum" no momento em que falava com a imprensa depois de uma derrota. Vários cenários de "violência espontânea" (WALGRAVE; LIMBERGEN, 1988) também foram registrados em ligas regionais nos anos estudados (2006-2018). Os fatos foram essencialmente similares: um cartão vermelho, um pênalti ou uma derrota que desencadeou brigas entre torcedores e/ou jogadores. Em 2013, na Liga regional da província de La Rioja, o jogador Franco Nieto foi atingido por uma pedra e morreu minutos depois. A capacidade das forças policiais, além de insuficientes, muitas vezes entram em ação não para conter os conflitos, mas suas ações agressivas aumentam a raiva dos envolvidos.

As brigas coletivas de jogadores nos campos têm sido uma constante em diferentes categorias de futebol. No verão de 2016, por exemplo, o jogo entre Gimnasia e Estudiantes de la Plata, na cidade de Mar del Plata, precisou ser suspenso por uma rixa entre jogadores. Estes episódios se mostram com certa regularidade nos jogos de categorias de base tanto na Argentina quanto no Brasil. Em Goiânia, um jogo sub-20 entre dois times da cidade provocou, em 2018, uma série de cenas violentas entre jogadores que circularam na televisão. Este aspecto mereceria em si um estudo inteiro dedicado à avaliação dos fatores que entram em jogo nas brigas, algumas "espontâneas", certamente por conta de situações tensas nas partidas, outras provocadas pelos torcedores nas arquibancadas, ou pelos jogadores que trocam insultos com eles. Nesse clima, são as vezes os própios parentes dos protagonistas que incitam à agressões. Na Argentina, Emiliano Monti, um goleiro de uma liga regional da província de Córdoba, perdeu sua vida em novembro de 2013 depois de um espancamento brutal por seus adversários em julho do mesmo ano. Em setembro de 2015, Matias Minanfra, um jovem jogador do All Boys (16 anos de idade) do foi atingido com uma pedra, como consequência de uma batalha em massa com os jogadores do Chacarita, seus familiares e "amigos" na arquibacada. Em março de 2017, Fernando Pereiras, um treinador de futebol de salão, morreu em um hospital em Buenos Aires depois de ter sido agredido pelo tio de um jogador rival. Nestes confrontos, o levantamento da Salvemos tem registrado situações onde alguns membros das barras se apresentaram nas cenas de combate junto com jogadores ou membros da família (sendo alguns deles, lógico, pais dos garotos no campo (SEGURA; MURZI; NASSAR, 2018: 13)). Como podemos inferir a partir de todos estes cenários complexos, a violência, nos seus diferentes níveis no futebol, não é uma exclusividade de um determinado grupo. Em outros termos, não é propriedade das barras ou das torcidas organizadas, como se pensa na maioria dos estúdios de televisão, rádio e imprensa na Argentina e no Brasil.

\section{ALGUMAS REFLEXÕES ENTRE A ARGENTINA E O BRASIL}

Em primeiro lugar, o fato de refletir sobre o clima geral de violência que envolve o futebol da Argentina, além da espetacular atmosfera, a estética, os cantos e o apoio dos hinchas, reveste também um alto grau de agressividade masculina. Isso, da mesma forma que Eric Dunning e seus colaboradores sublinharam para a época dos hooligans na Inglaterra (DUNNING; MURPHY; WILLIAMS, 1986) como um ambiente de hiper-masculinidade prevalecente tanto dentro quanto fora do campo por décadas (AWARDS; WILLIAMS: 2009). Essa situação ligada a uma masculinidade dominante (FERNANDES, 2019) foi observada entre 2017 e 2019 nos estádios de Goiânia, no Brasil ${ }^{12}$. A partir daqueles quadros de mortes identificados pelos

\footnotetext{
${ }^{12}$ Sugerimos esta hipótese também para explorar outros contextos regionais nos estados, capitais e cidades do Brasil.
} 
pesquisadores Archetti e Romero (1994), quando os núcleos duros das barras e a estrutura violenta do futebol argentino tomou suas raizes, outros estudos, posteriores, têm encontrado diferentes e variantes características no decorrer do século XXI. Quanto aos membros das barras, embora eles sejam considerados como sujetos marginais pelos meios de comunicação e pelas políticas públicas (GARRIGA, 2006), sua capacidade para se adaptar aos clubes, sindicatos e até às lógicas dos partidos políticos na Argentina (BERGES, 2015; D'ANGELO, 2012; CANTERO, 2014; GARRIGA, 2013; MOREIRA, 2012; MURZI, 2011; 2019) demonstra que os enredos da violência na Argentina vão bem além do espaço social (BOURDIEU, 1981) do futebol. Para o leitor de língua portuguesa, talvez chegue até a supreender o fato que o único jornal nacional dedicado ao esporte (sobretudo ao futebol masculino), Olé, apresente uma seção fixa dedicada às "barras bravas". Porém, os dados ali detalhados nem sempre constituem incidentes violentos, mas apenas atividades ordinárias de uma barra brava, o que permite ver, ao pesquisador em ciências sociais, que para uma importante parte da imprensa existe uma relação automática entre os termos "barras bravas" e "violência".

Ora, no que se refere as hipóteses acima propostas, podemos inferir, no entanto, que o uso da violência física, a qual pode por vezes resultar em mortes, têm mudado de formas e tendências a respeito do que prevalecia entre as décadas de 1950 e o final dos anos 1990, particularmente na Argentina. O crescimento de conflitos intra-faccionários dentro de uma mesma arquibancada representa, hoje, o principal número de incidentes fatais. $\mathrm{O}$ "maior" inimigo, ou "outro", já não se situa sempre no lado oposto, especialmente quando a política pública de torcida única tem, sob a ótica destas reflexões, incentivado os conflitos internos nos diferentes grupos que procuram ocupar posições. Este fato social, que não pode ser negado, reforça a segunda hipótese proposta e se insere na linha de estudos que indica que a forma de lidar com o futebol e a segurança precisa ser reconsiderada há anos (ALABARCES, 2004; ARAGÓN, 2007; GALVANI; PALMA, 2005; GARRIGA; MURZI; ROSAS, 2017; MURZI, 2014 SAIN; RODRÍGUEZ, 2014; SEGURA; MURZI, 2015; ULIANA E GODIO, 2013). Como o pesquisador brasileiro Taddei (2016) afirma, existe um estado geral de neurose entre polícia e torcedores na Argentina.

Porém, apesar do número significativo de episódios identificados longe dos estádios, não podemos sustentar a terceira hipótese. Vários confrontos brutais entre torcedores da mesma arquibancada foram resolvidos no interior do estádio. Igualmente preocupante, as agressões coletivas que envolvem outros atores, isto é, não-membros das barras, são muitas vezes desencadeadas devido à divergências sobre decisões e resultados esportivos. Estes episódios pressupõem que o fator do desempenho não deve ser abandonado como uma das explicações da violência. Precisamos, em tal sentido, distinguir duas características: quando torcedores atacam fisicamente, intimidam ou jogam objetos contra jogadores ou qualquer figura de autoridade, por um lado, e outros cenários que atraiam brigas entre os jogadores e seus familiares. Em suma, e ao contrário da interpretação hegemônica dos meios de comunicação social que considera as barras como o "câncer" a ser extirpado na Argentina, uma das conclusões deste trabalho é que diferentes formas de violência são também cometidas por outros atores. Não existe um setor ou grupo violento per se por um lado, e uma sociedade "puritana", "não-violenta", por outro. Por conseguinte, as vítimas e o contexto de suas vidas constituem uma outra dimensão que requer mais atenção. É claro que no presente trabalho temos analisado apenas partes de um problema complexo. No futuro, é necessário discernir diferentes quadros, sugerir novas hipóteses e recolher dados tanto para o contexto argentino quanto para o brasileiro. Outros padrões a serem identificados podem sugerir novos elementos representativos.

$\mathrm{Na}$ Argentina, o futebol faz parte de uma história importante para a cultura popular e para os interesses de certas elites (PALOMINO; SCHER, 1988). A sua violência não é um fenômeno homogêneo, considerando que existem uma variedade de situações e diferentes modus operandi. De acordo com Aragón (2017), o microcosmo das barras também reflete lógicas neoliberais econômicas que tem prevalecido ao longo de décadas no país. Num contexto onde a sobrevivência é um desafio com base em méritos individuais, e muitas vezes anti-éticos, a competição exacerbada entre os grupos e as lideranças da mesma arquibancada pode ser apenas uma reprodução mais 
ampla de características econômicas, políticas e sociais da vida cotidiana. O leitor deve lembrar que quando os escândalos de corrupção no seio da FIFA explodiram em 2015, vários indivíduos e empresas envolvidas operavam em conexões com a Argentina e com o Brasil. Portanto, existem outros problemas que merecem atenção, tais como as possíveis relações corporativas e corrupção no futebol. Os grandes meios de comunicação parecem haver descoberto estes indíviduos e empresas, que por anos foram seus parceiros comercias e pessoas "VIP".

Apesar da neurótica atenção da mídia em incidentes que envolvem torcedores, e isto vale mais uma vez tanto para Argentina quanto para o Brasil, talvez esteja chegando a hora para dar maior voz ao público que frequenta os estádios. Novas associações civis têm se criado nos dois países. No Brasil, a experiência da Associação Nacional de Torcidas Organizadas (ANATORG) apareceu como uma novidade e uma tentativa de diálogo, entre as organizadas e as autoridades (SEGURA; TEIXEIRA, 2016; TEIXEIRA, 2018). Na Argentina, surgiu em 2016 a Coordinadora de Hinchas, um coletivo que busca defender os direitos dos hinchas frente as novas medidas repressivas e as tentativas de privatizar os clubes, sendo que estes são na Argentina, na maioria dos casos, associações civis. Ficam vários temas pendentes, como a homofobia no futebol e a possibilidade de criar espaços mistos nos estádios entre torcedores rivais, como se faz nos jogos entre Grêmio e o Inter de Porto Alegre. Aprender com os sucessos de outros países, embora os contextos sejam diferentes, também pode dar uma maior imaginação aos assuntos de gestão da segurança. Existem trabalhos que tem analisado o enfoque britânico e o belga (SEGURA; MURZI, 2015), assim como estudos em português que examinam a experiência de políticas públicas na Alemanha (TEIXEIRA; LOPES; 2018). Devemos, talvez, ver da mesma forma o que acontence em países latinoamericanos como a Colômbia (VILLANUEVA, 2013). Através de pesquisas nas ciências sociais acreditamos que existem ferramentas disponíves e estímulos para discussões mais profundas sobre políticas públicas assim como para o debate midiático. Cabe nos perguntar se existe um verdadeiro interesse dos atores que desenvolvem as políticas públicas, assim como de aqueles geradores de "opinião pública", para dialogar com as ciências sociais. Os autores deste texto acham que a criação de pontes de diálogo com esses atores é fundamental para reduzir a violência no futebol. A última reflexão, sobre a qual os autores deste texto estão trabalhando para artigos futuros, tem a ver com os compromissos dos própios clubes com seus torcedores e, em termos mais gerais, com seus bairros e comunidades. Nesse sentido, temos muito a aprender com os Community Programs na Inglaterra. Este assunto será o objeto de ulteriores publicações como resultado de uma pesquisa em andamento no seio de alguns clubes ingleses, em particular o Sheffield United e o Leicester City ${ }^{13}$.

\section{REFERÊNCIAS}

ALABARCES, PABLO. Crónicas del Aguante. Fútbol, violencia y política. Buenos Aires: Capital Intelectual, 2004.

ALABARCES, PABLO. La violencia, la academia y el fracaso. In: GARRIGA, JOSÉ. Violencia en el Fútbol. Buenos Aires, Argentina: Godot, p. 21-38, 2013.

ARAGON, SILVIO. Los trapos se ganan en combate. Buenos Aires: Antropofagia, 2007.

ARAGON, SILVIO. Neoliberalismo, construção de novas subjetividades e violência do futebol argentino. In: RODRIGUEZ, ONESIMO; HOLLANDA, BERNARDO. Torcidas Organizadas na América Latina. Rio de Janeiro: 7 Letras, p. 65-75, 2017.

ARCHETTI, EDUARDO. Fútbol y Ethos. Monografías e Informes de Investigación, Buenos Aires: FLACSO, No.7, 1985

ARCHETTI, EDUARDO. Argentinian Soccer: A ritual of violence? In: The International Journal of the History of Sport, 1992, Vol.9, No. 2, p. 209-232.

ARCHETTI, EDUARDO. Masculinities: Soccer, Polo and Tango in Argentina. Grand Rapids, MI: Berg, 1999.

ARCHETTI, EDUARDO; ROMERO, AMÍLCAR. Death and violence in Argentinian football. In.: GIULIANOTTI, RICHARD; BOONEY, NORMAN; HEPWORTH, MIKE (Eds.). In: Football, Violence and Social Identity. Londres: Routledge, 1994.

ARMSTRONG, GARY; HARRIS, ROSEMARY. Soccer hooligans. In: Theory and evidence. Sociological Review, 1991, Vol. 39, No. 3, p. 427-567.

\footnotetext{
${ }^{13}$ Pesquisa em andamento em parceria entre Fernando Segura, David Wood (Universidade de Sheffield) e John Williams (Universidade de Leicester) em andamento entre setembro 2018 e novembro 2019.
} 
BARNADE, OSCAR; IGLESIAS, WALDEMAR. Mitos y Creencias en el Fútbol Argentino. Buenos Aires, Argentina: Arco, 2006.

BERGES, MARIANO. Sobre el Rafa Di Zeo, Mauricio Macri y la 12. In: MONICA, NIZZARDO; MARIANO, BERGES. Salvemos al Fútbol. Buenos Aires: Dunken, 2015.

BOURDIEU, PIERRE. Comment peut-être sportif? In : Question de Sociologie. Paris, La Découverte, 1981.

BRAUN, ROBERT; VLIEGENTHART, RENS. The Contentious fans: The impact of reppression, media coverage, grievance and aggressive play on supporters' violence. International Sociology, 2008, No. 23, p. 796-818.

BUNDIO, JAVIER. Redes negativas: el pequeño mundo de las hinchadas. In: Redes, 2013, Vol.24, No. 2, p. 109-134.

BUNDIO, JAVIER. Un análisis del contenido y la melodía de los cantos de cancha desde sus orígenes hasta las tendencias actuales. In: LEVORATTI, ALEJO, MOREIRA, VÉRONICA. (Eds.), Deporte, Cultura y Sociedad. Estudios socio-antropológicos en Argentina. Buenos Aires: Ediciones Godot, 2016.

CABRERA, NICOLAS. De corporalidades masculinas, aguantadoras y populares. Violencia, identidad y poder en la hinchada del Club Atlético Belgrano. In: GARRIGA, JOSÉ. Violencia en el Fútbol. Buenos Aires: Godot, 2013.

CANTERO, JAVIER. Contra el Sistema: EI Lado Oscuro del Fútbol. Buenos Aires: Planeta 2014.

CARRION, FERNANDO. Violencia en el fútbol: razones de una sinrazón. In: CARRION, FERNANDO; RODRIGUEZ, MARIA JOSÉ. Luchas urbanas Alrededor del Fútbol. Quito: 5ta Avenida Editores, 2013.

CARROZZA, PABLO. "Yo no soy como esos": Negocios, Traiciones y Muerte en la Barra de River. Buenos Aires: Planeta, 2015.

CASTRO, JOHN ALEXANDER. El Carnaval y el combate hacen el aguante en una barra brava. Revista Colombiana de Sociología, 2013, V.33, No. 1, p. 77-92,

CHAPIETTA, JULIO. Esa madre, esas luchas. In: MONICA, NIZZARDO; MARIANO, BERGES. Salvemos al Fútbol. Buenos Aires: Dunken, 2015.

COMERON, MANUEL. The Prevention of Violence in Sport. Strasbourg: Council of Europe. 2002.

CONDE, MARIANA. La invención del hincha en la prensa deportiva. In: ALABARCES, PABLO. Hinchadas. Buenos Aires: Prometeo, 2005.

CZESLI, FREDERICO. Apuntes sobre la identidad en la hinchada de Platense. In: GARRIGA, JOSÉ. Violencia en el fútbol. Buenos Aires: Godot, 2013.
D'ANGELO, NATALIA. La nueva conflictividad en las barras bravas en Argentina: una lectura a la luz de la teoría de redes. In: Revista de Investigación Social, 2012, Vol.8, No. 13 , p. 55-75.

DEL FRADE, CARLOS. Central, Nuls: La Ciudad Goleada. Fútbol, lavado de dinero y poder. Tomo II. Rosario: Último Recurso, 2008.

DUKE, VIC; CROLLEY, LIZ. Fútbol, politicians and the people: Populism and politics in Argentina. In: The International Journal of the History of Sport, 2011, Vol.18, No. 3, p. 93-116.

DUNNING, ERIC. Towards an Understanding of Football Hooliganism as World Phenomenon. In: The European Journal on Criminal Policy and Research, 2000, Vol.8. No. 2, p. 141-162.

DUNNING, ERIC; MURPHY, PATRCK; WILLIAMS, JOHN. Spectator violence at soccer matches: Towards a sociological explanation. In: ELIAS, NOBERT; DUNNING, ERIC. Quest for Excitement. Oxford: Blackwell, 1986.

EHREMBER, ALAIN. Le culte de la Performance. Paris: Hachette, 1991.

ELIAS, NORBERT; SCOTSON, JOHN. Les Logiques de I'Exclusion : Enquete sociologique au coeur des problèmes d'une communauté, Paris : Fayard, 1997.

FERNANDES LEME, LUIZ. O Preconceito Dentro e Fora das Quatro Linhas: O Papel dos Jornalistas Goianos. Dissertação de Mestrado em Comunicação, Universidade Federal de Goiás, 2019.

FRYDEMBERG, JULIO. Historia social del fútbol en Argentina. Buenos Aires: Siglo XXI, 2012.

GAFFNEY, CRISTOPHER. Stadiums and society in twentyfirst century Buenos Aires. In: Soccer \& Society, 2009, Vol.10, No. 2, p. 160-182.

GALVANI, MARIANA; PALMA, JAVIER. La hinchada de uniforme. In: ALABARCES, PABLO. Hinchadas. Buenos Aires: Prometeo, 2005.

GANDARA, LELIA. Las voces del futbol: análisis del discurso y cantos de cancha: EFDeportes, 1997, p. 1-20.

GARRIGA, JOSÉ. Haciendo amigos a las piñas: violencia y redes sociales en una hinchada de fútbol. Buenos Aires: Prometeo, 2006.

GARRIGA, JOSÉ. Cartografías de la(s) violencia(s). In.: GARRIGA, JOSÉ. Violencia en el fútbol: investigaciones sociales y fracasos políticos. Buenos Aires: Godot, 2013.

GARRIGA, JOSÉ; DIEGO, MURZI; ROSA, SEBATIÁN. Enemigos Íntimos. Anfibia (online), Junho 2017.

GIL, GASTON. Hinchas en tránsito. Mar del Plata: EUDEM, 2007. 
GINHOUX, BERANGERE. « Liberté pour les Ultras »: analyse sociologique des réseaux. In: BUSSET, THOMAS; GASPARINI, WILLIAMS (Eds.). Aux Frontières du Football et du Politique. Berna: Peter Lang, 2016.

GLORIZOVA, EKATERINA. Soutenir et contester: les thèmes supportéristes comme vecteurs de politisation en Russie. In: BUSSET, THOMAS; GASPARINI, WILLIAMS (Eds.). Aux Frontières du Football et du Politique. Berna: Peter Lang, 2016

GODIO, MATÍAS; ULIANA, SANTIAGO. Aportes para una nueva experiencia de la seguridad en los estadios del fútbol argentino. In: Revista Brasileira de Tecnologias Sociais, 2016, Vol.3, No. 1, p. 71-82.

GOFFMAN, ERVING. The Presentation of the Self in Everyday Life. New York: Anchor, 1959

HOBBS, DICK; ROBINS, DAVID. The boy done good: Soccer violence, changes and continuities. In: Sociological Review, 1991, Vol.39, No. 3, p. 551-579.

HOLLANDA, BERNANDO, Hooliganismo e Copa de 2014. Rio de Janeiro: 7 Letras, 2014.

HOLLANDA, BERNARDO. Torcidas, hinchadas e barras: A problemática torcedora em escala continental. In: RODRIGUEZ, ONESIMO; HOLLANDA, Bernardo. Torcidas Organizadas na América Latina. Rio de Janeiro: 7 Letras, 2017.

INGHAM, ROGER. Soccer Hooliganism. London: InterAction Imprint, 1978.

KERR, JOHN. UNDERSTANDING HOOLIGANISM. Bristol: Open University Press, 1994.

LEVINSKY, SERGIO. AFA: El Fútbol Pasa, Los Negocios Quedan. Buenos Aires: Autoria, 2016.

MARSH, PETER. Aggro: The Ilusion of Violence. London: Dent., 1978.

MIGNON, PATRICK. La Passion du Football. Paris: Odile Jacob, 1998.

MORALES, VICTOR HUGO. El Rebenque del Diablo. Buenos Aires: Colihue, 2015.

MOREIRA, VERÓNICA. Trofeos de guerra y hombres de honor. In: ALABARCES, PABLO. Hinchadas. Buenos Aires: Prometeo, 2005.

MOREIRA, VERÓNICA. Juego electoral y relaciones políticas en el fútbol argentino. In: Questões \& Debates, 2012, No.57, p. 127-149.

MURAD, MAURICIO. Práticas de violência e mortes de torcedores no futebol brasileiro. In: Revista UPS, 2013, No. 99, p. 139-152.

MURAD, MAURICIO. A Violência no Futebol, São Paulo: Benvirá, 2017.
MURZI, DIEGO. Hooligan or business man? Portrait des supporters de football violents en Argentine. Mémoire de master II - Ecole des Hautes Etudes en Sciences Sociales, Paris, 2011.

MURZI, DIEGO. Fútbol, Violencia y Estado: Un Estudio sobre las Políticas Públicas de Seguridad Deportiva en Argentina (2006 -2017). Tese de Doutorado em Ciências Sociais, Universidade de Buenos Aires, 2019.

MURZI, DIEGO; SEGURA, FERNANDO. Violences dans les stades en Argentine: la place des «barras-bravas» et la réaction citoyenne. In: BUSSET, THOMAS; BESSON, ROGER; JACCOUD, CHRISTOPHE (Eds.). L'autre visage du supportérisme. Berna: Peter Lang, 2014.

MURZI, DIEGO; SUSTAS, SEBASTIÁN; ULIANA, SANTIAGO. La violencia en el fútbol desde las ciencias sociales. In: NIZZARDO, MÓNICA; BERGES, MARIANO (Eds.). Salvemos al Futbol. Buenos Aires: Dunken, 2015.

MURZI DIEGO; SEGURA FERNANDO. Hacia un Mapa de las "Violencias en el Fútbol": Actores, Dinámicas, Respuestas Públicas y Desafíos en el Caso de Argentina. In: Revista de Gestión Pública, 2018, Vol.7, No. 1, p. 43-75.

NIZZARDO, MÓNICA; BERGES, MARIANO. Salvemos al Fútbol: 10 años de vida. Buenos Aires: Dunken, 2015.

NEWSON, MARTHA. Football, Fan Violence and Identity Fusion. In: The International Review for the Sociology of Sport, 2017, On-Line-First, 1-14.

PALOMINO, HECTOR; SCHER, ARIEL. Fútbol, pasión de elites y multitudes: estudio institucional de la Asociación de Fútbol Argentino (1934-1986). Buenos Aires: CISEA, 1988.

PARRISH, CHARLES; NAURIGHT, JOHN. Fútbol cantitos: Negotiating masculinity in Argentina. In: Soccer \& Society, 2013, Vol.14, No. 1, p. 1-19.

REDHEAD, STEVE. Some reflections on discourses on soccer hooliganism. In: Sociological Review, 1991, Vol.30, No. 3, p. 480-486.

ROMEO, AMÍLCAR. Deporte, violencia y política. Buenos Aires: Centro Editor de América Latina, 1985.

ROMERO, AMÍLCAR. Muerte en la Cancha. Buenos Aires: Editorial Nueva América, 1986.

ROMERO, AMÍLCAR. Las Barras Bravas y la Contrasociedad Deportiva. Buenos Aires: Editorial Nueva América, 1994.

SAIN, MARCELO; RODRÍGUEZ, NICOLÁS. Los actores y la seguridad en el fútbol. In: CARRIÓN, FERNANDO; RODRÍGUEZ, MARIA JOSÉ. Luchas Urbanas Alrededor del Fútbol. Quito: 5ta. Avenida Editores, 2014.

SEGURA, FERNANDO. Ritualización y mercantilización de la violencia en el fútbol: elementos comunes y diferencias 
entre las barras de Argentina y México. In.: Documento de trabajo DAP, (CIDE, DAP), 2013, No.267, p. 1-47.

SEGURA, FERNANDO; MURZI, DIEGO. ¿Gestión de la violencia en el fútbol? Perspectivas críticas sobre Inglaterra y Bélgica. In: Revista de Gestión Pública, 2015, Vol.4, No. 1, p. 65-106.

SEGURA, FERNANDO; MURZI, DIEGO; YOSHIDA, LAURA. Entre a Violência e a Festa Popular no Futebol da Argentina. In: Publicatio Ciências Sociais, 2017, Vol.25, No. 2, p. 163-173.

SEGURA, FERNANDO; MURZI, DIEGO; NASSAR, BELEN. Violence and Death in the Argentinean Soccer. In: The International Review for the Sociology of Sport, 2018, On-Line-First, 1-18.

SODO, JUAN. De la violencia a los ambientes de violencia: entre el doble discurso de los hinchas y el doble reduccionismo mediático. In.: GARRIGA, JOSÉ (Ed.). Violencia en el fútbol. Buenos Aires: Godot, 2013.

SPAAIJ, RAMON. Understanding Soccer Hooliganism. Amsterdam, The Netherlands: Amsterdam University Press. 2016.

STOTT, CLIFFOR; ADANG, OTTO; LIVINSTONG, ANDREW; SCHREIBER, MARTINA. Tackling Football Hooliganism: A Quantitative Study of Public Order, Policing and Crowd Psychology. In: Psychology, Public Policy and Law, 2008, Vol.14, No. 2, p.115-141.

SUSTAS, SEBASTIAN. Las violencias sentenciadas. In: GARRIGA, JOSÉ. Violencia en el Fútbol. Buenos Aires: Godot, 2013.

SZLIFMAN, JAVIER. La Fiesta Que No Fue. Un Análisis Sobre Los Medios De Comunicación Y La Violencia En El Fútbol Argentino. Buenos Aires: EFDeportes, 2010.

TADDEI, RENZO. La invención de la violencia (de las hinchadas de Buenos Aires). Antípoda, Revista de Antropología y Arqueología, 2016, No. 24, p. 15-33.

TEIXEIRA, ROSANA. Os Perigos da Paixão: Visitando Torcidas Jovens Cariocas. São Paublo, Annablume, 2004.

TEIXEIRA, ROSANA; LOPES, FELIPE. Reflexões sobre o Projeto Torcedor Alemão. In: Revista de Antropologia São Paulo, 2018, Vol.61, No. 3, p. 130-161.

TAYLOR, IAN. Football Mad - Speculative Sociology of Soccer Hooliganism. In.: DUNNING, ERIC (Ed.). The Sociology of Sport: A Selection of Readings. Londres: Cass, 1971.

TSOUKAKA, ANASTASSIA. Hooliganisme en Europe. Paris: Athena, 2010.

ULIANA, SANTIAGO; GODIO, MATÍAS. Separar, dividir y mortificar. In: GARRIGA, JOSÉ (Ed.). Violencia en el fútbol. Buenos Aires: Godot, 2013.
VILLANUEVA, ALEJANDRO. Aspectos Legales, Jurídicos y Normativos en las Barras Futboleras en Bogotá y Colombia. In: GARRIGA, JOSÉ. Violencia en el Fútbol. Buenos Aires: Godot, 2013.

WALGRAVE, LODE; LIMBERGEN, KRIS. Le hooliganisme belge. Revue Interdisciplinaire d'Études Juridiques, 1988. No Spécial: p. 7-31.

WARD, ANDREW; WILLIAMS, JOHN. Football Nation: Sixty Years of the Beautiful Game. Londres: Bloosbury, 2009

WIEVORKA, MICHEL. Préface. In: ELIAS, NORBERT; SCOTSON, JOHN. Les Logiques de I'Exclusion : Enquete sociologique au coeur des problèmes d'une communauté, Paris : Fayard, 1997.

WILLIAMS, JOHN; DUNNING, ERIC; MURPHY, PATRICK. Hooligans Abroad. London: Routledge, 1984.

ZALUAR, ALBA; MONTEIRO, RODRIGO. Torcer, Lutar, O Inimigo Masscrar: Raça Rubro-Negra! Rio de Janeiro: FGV, 2013. 